\title{
FEMALE SEXUAL DYSFUNCTION: THE IMPORTANT POINTS TO REMEMBER
}

\author{
Eleonora B. Pasqualotto, Fabio Firmbach Pasqualotto, Bernardo P. Sobreiro and \\ Antonio Marmo Lucon
}

PASQUALOTTO EB et al. Female sexual dysfunction: the important points to remember. CLINICS 60(1):51-60, 2005.

Media exposure regarding male sexual dysfunction and the growing number of viable treatment alternatives for erectile dysfunction has resulted in increasing numbers of men seeking clinical appointments and treatment for the condition, which has previously been considered taboo. Because these problems usually arise within the context of relationships, some investigators have alluded to increased rates of sexual dysfunction among the partners of these men. Also, since general practitioners, gynaecologists, geriatrists, and urologists are also seeing female patients for evaluation of various types of dysfunction, certain groups of these women with underlying chronic conditions have been noted to have high rates of concomitant sexual dysfunction. Physicians who have good rapport with these patients are in a privileged position to help with these intimate problems, which are often difficult for patients to discuss. Therefore, it is of extreme importance that these professionals become knowledgeable about and comfortable with the initial evaluation and possible treatment of female sexual dysfunction.

KEYWORDS: Women. Female. Sexual. Dysfunction.

There is an ongoing change in the field of female sexual function and dysfunction. ${ }^{1,5}$ The number of general practitioners, researchers, and institutions treating female sexual dysfunction (FSD) appears to be growing every year. ${ }^{6-8}$ General practitioners, gynecologists, geriatrists, and urologists are attending groups of women with underlying chronic conditions with increased rates of concomitant sexual dysfunction. ${ }^{5,9,10}$ Physicians who have a good rapport with these patients are in a unique position to help with these intimate problems, which are often difficult for patients to discuss. Therefore, it is of utmost importance to general practitioners, gynecologists, geriatrists, and urologists to become knowledgeable about and comfortable with the initial evaluation and possible treatment of FSD.

From the University of Caxias do Sul - Caxias do Sul/RS, Brazil and the Urological Clinic, Hospital das Clínicas, Faculty of Medicine, University of São Paulo - São Paulo/SP, Brazil.

E-mail: pasquaf@hotmail.com

Received for publication on September 01, 2004.

Accepted for publication on October 15, 2004.

\section{Prevalence of Female Sexual Dysfunction}

Sexual dysfunction can be defined as "the persistent impairment of a couple's normal or usual patterns of sexual interest and/or response". Pioneering works by Kinsey in 1953 and, subsequently, Masters and Johnson in 1966 provided insights into the range of normative sexual function and the physiologic processes underlying sexual stimulation. ${ }^{11}$ Since these studies, the media have popularized the results of these and other studies, challenging many myths and turning the human sexual function into a daily topic of conversation, while at the same time possibly indicating false standards of normalcy through the misrepresentation of data. For instance, misinterpretation of Masters and Johnson's research on multiple orgasms in the female may result in feelings of inadequacy and dysfunction in a woman who does not experience multiple orgasms. ${ }^{12}$ Welldesigned, randomly-sampled, community-based epidemiologic investigations of women with sexual dysfunction are limited. Current data reveal that up to $76 \%$ of women have some type of sexual dysfunction. The U.S. population cen- 
sus data suggest that nearly 10 million American women aged 50 to 74 self-report complaints of diminished vaginal lubrication, pain and discomfort on intercourse, decreased arousal, and difficulty in achieving orgasm. ${ }^{13,14}$ Recently, Laumann and Rosen found that sexual dysfunction is more prevalent in women (43\%) than in men (31\%) and is associated with various psychodemographic characteristics such as age, education, and poor physical and emotional health. ${ }^{15}$ More importantly, FSD is associated with negative sexual relationship experiences. Despite the high prevalence of sexual dysfunction in women, there are very few centers worldwide that practice comprehensive and multidisciplinary investigation and management of sexual dysfunction in women.

There are few data regarding the incidence and prevalence of FSD. Presently available epidemiologic studies of sexual dysfunction suffer from a variety of methodological problems, including small sample size, skewed sample populations, failure to sample nonresponders, and lack of a uniform definition of sexual dysfunction. These shortcomings notwithstanding, Hawton states that women report more sexual problems than men, with a prevalence rate of $35 \%$ to $60 \%$; disorders of desire and arousal are the most common complaints. ${ }^{16}$

Age and relationship status are significant predictors of sexual satisfaction, with older women reporting a higher prevalence of sexual difficulty. ${ }^{17-19}$ Also, despite their sexual difficulties, more than half of women reported being from somewhat to very satisfied with their overall sexual relationship. Therefore, relationship satisfaction for women may not be determined entirely by sexual function. Moreover, many women may tolerate a certain level of sexual dysfunction before considering it a source of relationship dissatisfaction.

\section{Evaluation of Female Sexual Dysfunction}

In some cases, it may be necessary for physicians to carefully inquire into sexual functioning, paying special attention to the sensitivity of the topic and to the patient's com- fort levels. Validated sexual questionnaires, such as the Female Sexual Function Index ${ }^{20}$ and the Sexual Distress Scale ${ }^{21}$ may be helpful tools in the evaluation of sexual function. The cornerstone of the patient evaluation is a comprehensive and detailed sexual, medical, and psychosocial history; physical examination; and focused laboratory testing $22-25$ are essential. Specialized diagnostic tests such as biothesiometry or genital vascular studies (duplex Doppler ultrasound), although not always indicated, may corroborate the impressions gained at the initial evaluation. It should be stressed that the secondary psychological reaction to these organic factors must not be ignored. ${ }^{24,25}$

Despite the prevalence of FSD, many women may be too embarrassed or reluctant to initiate a discussion of their sexual problems. ${ }^{1-4}$ Unassuming questions such as, for instance "Are you sexually active?" followed by "Do you have any questions or concerns regarding your sexual health?" may be all that is needed to establish confidence in a rapport leading to further inquiry. The more longstanding the sexual dysfunction, the more difficult it becomes to treat. Since general practitioners, gynecologists, geriatrists, and urologists will be seeing an increasing number of women with either overt or covert sexual dysfunction, it has become prudent to learn how best to treat or refer appropriately.

Assessment of FSD begins with a thorough case history, physical examination, and appropriate laboratory studies (Table 1). In addition, it must be determined whether these problems are new or chronic in duration, arise from specific or more general situations, or are byproducts of a relational or deep-rooted emotional conflict.

\section{History}

Delineate any prior history of childhood sexual abuse, incest, rape, or sexual harassment, and arrange for appropriate counseling (Table 1). ${ }^{26-29}$ Sexual expectations of both partners should be assessed for compatibility. Also, seek overt or covert current relationship or social or job stress that may be causing anxiety.

Table 1 - Evaluation of female sexual dysfunction.

\begin{tabular}{lll}
\hline Physical examination & History & Laboratory studies \\
\hline Senile atrophy vagina & Sexual abuse & Complete blood count \\
Vault erythema, discharge & Parity status & Thyroid-stimulating hormone \\
Prolapse & Menstrual status & Human immunodeficiency virus \\
Strictures, scars & Depression, anxiety & Urinalysis \\
Cervical motion tenderness & Comorbidities & Toxins \\
Bimanual examination & Abdominal, pelvic surgery & PAP smear \\
Levator ani myalgia & Medications & \\
Vulvar vestibulitis & Substance abuse & \\
\hline
\end{tabular}


There are several landmark physiological events in a woman's life that may affect her current sexual function. ${ }^{25,29}$ Sexual interest and activity often decline as pregnancy progresses, although there are few medical restrictions concerning coitus during pregnancy, except for the third trimester. Women who breast-feed may be more likely to report decreased sexual desire or increased coital pain. This may be secondary to the elevated prolactin levels that occur during lactation and inhibit ovarian function, resulting in lower testosterone (desire) and estrogen (vaginal discomfort) levels. There appears to be a biologically driven periovulatory peak of female sexual desire associated with increases in serum levels of testosterone and androstenedione. ${ }^{30}$

Although somewhat controversial, a number of reports associate menopause with decreased female sexual function, suggesting a possible hormonal mechanism for female sexual function; however, the exact hormonal milieu of normal female sexual function continues to be incompletely understood. ${ }^{13,16,18,27}$ Although estrogen replacement therapy may restore vaginal epithelial function, increase vaginal flow, and improve the overall sense of well-being in postmenopausal woman, it is not a guarantee of sexual well-being. ${ }^{31,32}$ Some researchers have documented a decrease in sexual desire believed to be secondary to testosterone deficiency in those premenopausal women who have undergone oophorectomy; however, postmenopausal women demonstrate more variability in hormone-sensitive sexual desire than testosterone-deficient men. ${ }^{32,33}$ In addition to hormonal changes, there are many psychosocial factors concomitant with the onset of the menopause, including questions of aging and body image that may have an impact on sexual function.

A variety of medical conditions have been associated with a disposition to FSD. ${ }^{1-3,34-37}$ Spinal cord injury may affect sexual function and, although controversial, women with spinal cord lesions at $\mathrm{T} 1$ and below are probably anorgasmic. ${ }^{1,29,36}$ In addition, women who have neurologic diseases such as Parkinson's disease or multiple sclerosis may have sexual problems. ${ }^{1,34}$ Chronic diseases affecting multiple systems such as thyroid dysfunction or diabetes may have an impact upon the female sexual function. ${ }^{38} \mathrm{~Pa}-$ tients who have had traumatic head injury may experience decreased sexual desire, and many temporal lobe epileptics have been shown to have a decreased sexual drive. ${ }^{24}$ Unfortunately, depression is a major risk factor for sexual dysfunction, and any chronic disease may result in depression, making delineation of etiology of sexual dysfunction somewhat problematic.

It is important to know whether the patient has any history of abdominal/pelvic trauma, sexually transmitted disease, or pelvic inflammatory disease. Prior surgical procedures including abdominal-perineal resection, pelvic ex- enteration, retroperitoneal lymphadenectomy, sympathectomy, or aortoiliac surgery may have either a mechanical or neurological effect on sexual function. ${ }^{4,6}$ Hysterectomy may foreshorten the vaginal vault or result in internal scarring that prevents full ballooning of the vagina. ${ }^{39,40}$ In addition, loss of the uterus results in diminished total vasocongestion and loss of uterine contractions with stimulation, which some women find bothersome. Whether supracervical hysterectomy preserves more complete sexual functioning, remains a matter of debate. Further, any history of prior pelvic radiation therapy may cause FSD.

Current knowledge regarding the sexual side effects of certain medications is not as well defined for women as it is for men. ${ }^{41,42}$ It is mainly the adverse sexual side effects of various psychotropic medications that have been characterized in women. ${ }^{42,43}$ Caution in evaluating these data is in order, because research indicates that many patients who have underlying psychiatric disorders may have had a low prior level of sexual function, and the sedative or extrapyramidal side effects of these medications may further limit the sexual function. ${ }^{44}$

Major tranquilizers such as diazepam are believed to limit sexual function secondary to a dopaminergic action. Antipsychotic medications such as thioridazine and fluphenazine have been reported to cause orgasmic dysfunction. ${ }^{25,41-43}$ Antidepressant medications such as imipramine cause deleterious sexual side effects in up to $75 \%$ of patients treated. Selective serotonin reuptake inhibitors (SSRIs) seem to cause decreased sexual desire and inhibited orgasm more frequently than monoamine oxidase inhibitors or tricyclic antidepressants. Interestingly, treatment with fluoxetine has been reported to result in the production of the spontaneous sensation of orgasm. ${ }^{42,43}$ Alcohol and drugs of abuse can alter the sexual response. Occupational or environmental exposure to toxins such as lead, mercury, pesticides, and any vinyl chloride, among others, may also affect sexual function..$^{25}$

\section{Physical Examination}

In addition to a comprehensive physical examination, attention should be drawn to the female pelvic exam. ${ }^{4,6,8,28,29,37}$ Examine the introitus for signs of senile mucosal atrophy or discharge; the presence erythema, or of any signs suggestive of vaginitis should be noted..$^{24,29,38}$ Findings based on bimanual examination may suggest endometriosis, varices of the broad ligament, ovarian adhesions or tenderness, adnexal masses, or pelvic inflammatory diseases. Rectal tone, masses, and any tenderness or fluid in the posterior cul-de-sac should be evaluated. The posterolateral rectal support should be assessed for levator ani myalgia. ${ }^{40,45}$ 


\section{Laboratory Studies}

Laboratory evaluation must be tailored to the findings of the history and physical examination. ${ }^{24,38}$ A complete blood count may reveal anemia or suggest occult malignancy that may underly malaise, depression, and decreased libido. A fasting biochemical profile should prove useful in the evaluation of renal, adrenal, hepatic, pancreatic, thyroid, or parathyroid function. Urinalysis may reveal infection or occult diabetes. Optional but sometimes useful laboratory tests include thyroid-stimulating hormone, the hepatitis panel, testosterone, progesterone, LH, FSH, prolactin, hemoglobin A1C, erythrocyte sedimentation rate, human immunodeficiency virus, and serum toxin levels (such as lead or mercury). Performance of Pap smears or cervical and vaginal cultures should be based on the findings of the physical examination. Clinical suspicion should guide the use of imaging modalities such as ultrasonography and Computed Axial Tomography scan (CT).

Diagnostic modalities such as duplex Doppler ultrasound, vaginal and clitoral temperature, vibration sensory testing, and selective pudendal arteriogram expand physician's and patient's understanding of the pathophysiologic mechanisms of the SD; however disadvantages such as invasiveness, cost, the associated risks/complications, and the lack of normative data have limited the use of these specialized tests. ${ }^{11,24,38,46,47}$ Noninvasive vascular testing of women with sexual dysfunction has been reported by several investigators. These include vaginal photoplethysmography and genital duplex Doppler ultrasound. Vaginal photoplethysmography, the most widely used vascular testing technique, measures vaginal mucosal engorgement and vaginal blood volumes, providing quantitative data on the extent of vaginal vasocongestion. The major drawbacks of this diagnostic tool are that it produces arbitrary rather than absolute units of measurement. In addition, it is susceptible to subject movement artifact and baseline drift.

The role of duplex Doppler ultrasonography in the management of women with sexual dysfunction remains to be determined. However, several investigators have reported small patient series using duplex Doppler ultrasound before and after stimulation (visual and vibratory) as a diagnostic tool in females with sexual dysfunction. .11,24,38,46,47 $^{-1}$

Clitoral shaft diameter is measured from the medial tunica albuginea of the corporal body across the septum to the lateral tunica albuginea of the contralateral corporal body. ${ }^{38,47}$ The angle of the clitoral shaft formed by the suspensory ligament is the sonographic landmark used for volumetric measurements. Maintaining this sonographic landmark, the small parts probe is then swept laterally to evaluate the hypoechoic, ill-defined, carrot-shaped corpus spongiosum that possesses a thin, occasionally visualized tunica, and the corpus spongiosum diameter is measured. ${ }^{47,48}$ Hemodynamic data (peak systolic, end diastolic, and resistive index values) from the corpus spongiosum and cavernosal arteries are measured. One of the limitations of the current ultrasonographic methodology is the lack of the standardized use of topical vasoactive agents to maximize genital smooth muscle relaxation.

\section{What is normal sexual function?}

Originally, Masters and Johnson outlined a progressive 3-phase sexual response cycle, consisting of arousal, orgasm, and resolution. ${ }^{12}$ Subsequently, sexologists attempting to treat patients who chronically fail to initiate or respond to sexual stimuli added an initial phase of desire to the sexual response cycle. ${ }^{12,24,38}$ The American Psychiatric Associations' Diagnostic and Statistical Manual of Mental Disorders (DSM-IV) classifies the sexual response cycle in 4 related but neurophysiologically discrete phases: appetite, desire, or libido; arousal or excitement; orgasm or climax; and refractory or resolution. ${ }^{12}$ Currently, researchers are considering whether a fifth phase, namely satisfaction, would help to further distinguish certain patients with sexual dysfunction.

\section{Desire}

Sexual desire appears to be controlled by a dopaminesensitive excitatory center balanced against a serotonin-sensitive inhibitory center. ${ }^{38}$ In both males and females, testosterone is responsible for programming these centers in prenatal life and for maintaining their threshold of response. ${ }^{49-}$ ${ }^{51}$ Desire is modulated by connections between these centers and other parts of the brain. ${ }^{11,50}$ The net effect of these positive and negative influences modulates genital sexual response via impulses passing down the spinal cord to the reflex centers that govern excitement and orgasm.

\section{Excitement}

During the excitement phase, vascular engorgement occurs, mediated primarily by the parasympathetic nervous system. ${ }^{11,24,38}$ Genital changes include enlargement in the diameter and length of the clitoris, dilation of perivaginal arterioles with seeping of vascular transudate across the vaginal epithelium resulting in lubrication, and expansion of the upper half of the vagina. ${ }^{46,47}$ Estrogen is the hormone responsible for maintaining the vaginal mucosa and allowing transudation and lubrication to occur. Afferent stimuli 
travel via the dorsal nerve of the clitoris to the pudendal nerve to sacral centers. Efferent stimuli occur via the pelvic nerve to the uterovaginal plexus. ${ }^{11,24,38,46,47}$

\section{Orgasm}

During the orgasmic phase, a series of reflex clonic contractions of the elevator sling and related genital musculature occur, mediated primarily via the sympathetic nervous system. ${ }^{24,25}$ Extragenital reactions during orgasm include contraction of muscle groups throughout the body and elevations of heart rate, blood pressure, and respiratory rate..$^{38}$

Excitement and orgasm are reflexes. ${ }^{38}$ For the orgasmic reflex to be activated, the stimulus must be applied where the sensory nerve endings are located (primarily in the area of the clitoris), and stimulation must be of sufficient intensity and duration to reach the threshold for the reflex.

\section{What is sexual dysfunction?}

Sexual dysfunction in women is defined as any disorder related to sexual desire, arousal, orgasm, and/or sexual pain that results in significant personal distress and may have an impact on the quality of life. ${ }^{11}$ Although each specific condition can be defined separately in medical terms, there is a clinically significant overlap in afflicted patients. True sexual dysfunction is manifested by failure of one or more phases of the sexual response cycle: desire, excitement, and orgasm (Table 2). ${ }^{11,12}$ However, according to DMS-IV, sexual dysfunctions should be categorized with reference to the earliest phase of the sexual response cycle during which disruptions occur. ${ }^{24,38}$ Therefore, the management of patients with FSD begins with the identification and diagnosis of the problematic relationships and is based on the patient's self-report in conjunction with a clinical evaluation. $^{24}$ the disturbance frequently begins with orgasmic disturbance, but if neglected, loss of excitement and finally loss of desire may follow. Sexual dysfunction may be further subdivided into three categories: primary (realistic sexual expectations have never been met under any

Table 2 - Categories of female sexual dysfunctions.

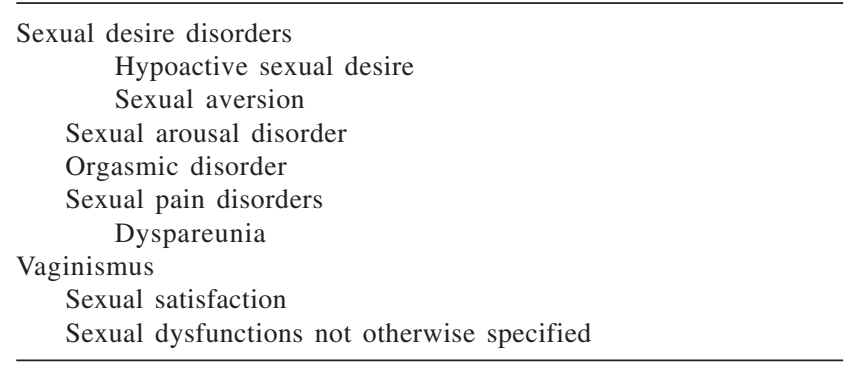

circumstances); secondary (all phases have functioned in the past, but one or more no longer do so); or situational (the response cycle functions in some circumstances, but not in others). ${ }^{37}$

The following is a brief discussion of the categories by which one may identify sexual dysfunction.

\section{Hypoactive Sexual Desire Disorder}

Some $30 \%$ to $50 \%$ of patients in sex therapy clinics present with complaints of hypoactive sexual desire disorder, defined as the persistent or recurrent absence or deficit of sexual activity. ${ }^{37,38,51}$ There are two major concerns in this diagnosis: 1) there are no norms for sexual desire stratified by age; and 2) the reasons for the development and maintenance of this complaint vary. This suggests that its etiology is heterogeneous.

Important physical factors that affect sexual desire include general health status, depression, hormonal status, and use of both prescribed and recreational drugs. ${ }^{41-44}$ Tricyclic antidepressants, monoamine oxidase inhibitors, lithium, and certain antipsychotics are among the medications reported to decrease sexual interest. ${ }^{42-44}$

Psychological and interpersonal factors are often involved. ${ }^{9,37}$ Such factors, which can diminish sexual desire, include sudden events such as job loss, or the loss of a family member; cumulative events such as a woman's response to aging and menopause; life milestones such as a child's leaving home; and ongoing relationship stress.

Appropriate treatment depends on the underlying etiology. Generalized and lifelong low sexual desire suggests the need for screening for endocrine disorders, chronic illness, or long-term medication use..$^{8,11,24,26,38}$ The use of testosterone has been shown to increase desire, but its longterm use may be limited by potential side effects including cardiovascular and liver dysfunction. Antidepressants may help depression-related low desire, although many of these medications at least initially decrease sexual desire. ${ }^{41-43}$

If there is no causative medical disorder, individual or couples therapy is often to be recommended. However, hypoactive sexual desire is one of the more difficult disorders to treat, with one study suggesting success rates of less than $50 \% .^{24}$ The more long-standing the disorder, the more resistant it is to treatment.

\section{Sexual Aversion Disorder}

Persistent or recurrent aversion to and avoidance of genital contact with a sexual partner; known as sexual aversion disorder, is a much less common disorder. ${ }^{38}$ Low sexual desire and occasionally vaginismus or dyspareunia usually 
accompany it. ${ }^{24,38}$ Women with this disorder may have a history of sexual or physical abuse. They may have extensive negative, unexpressed feelings about their relationships. ${ }^{9}$ Specific aversions that are phobic in nature, such as aversion to semen, may be difficult to overcome.

\section{Sexual Arousal Disorder}

Partial or total lack of physical signs of arousal during sexual stimulation in women without concomitant menopausal, dyspareunia, or anorgasmic symptoms is rare. ${ }^{24,36}$ Physical and subjective sexual arousal are not necessarily correlated in women. However, a continued lack of lubrication may lead to discomfort during sex, thus impairing a woman's subjective arousal, and could possibly be interpreted by her sexual partner as a lack of interest, which may eventually result in a distressed sexual relationship.

A thorough review of possible physical causes for this complaint constitutes the initial evaluation. ${ }^{11,37,38}$ Recommendations on the use of topical lubricants or estrogenic compounds should be based on the woman's physical condition, age, and risk factors for estrogen therapy. ${ }^{52,53}$

\section{Orgasmic Disorders}

Persistent delay in achieving orgasm or its absence is a common sexual complaint. ${ }^{24,25,37,38}$ Approximately $10 \%$ of women report a lifelong lack of orgasm, and at least $50 \%$ of women report situational or intermittent orgasmic problems.

Physical causes of orgasmic dysfunction may include pelvic or spinal surgery or trauma or the use of certain medications (such as various antidepressants and antipsychotics). ${ }^{24,36}$ Seldom does a physical cause underlie primary lifelong orgasmic disorder. Psychological and interpersonal factors, such as the woman's family values regarding sex or unpleasant earlier sexual experiences, may contribute to lack of orgasm. ${ }^{9}$ Male partners of anorgasmic women frequently feel responsible for the woman's lack of orgasm, which can further compound the relationship tension.

Effective treatments for orgasmic disorders include masturbation and traditional sex therapy techniques. Success rates in the $90 \%$ range for becoming orgasmic during masturbation and in the $75 \%$ range for attaining orgasm with a partner have been reported following therapy. ${ }^{24,25,27,37,38}$

\section{Dyspareunia}

Recurrent genital pain before, during, or after sexual intercourse is known as dyspareunia. ${ }^{11,38} \mathrm{~A}$ careful physical examination to precisely identify the anatomic sites and the abnormalities causing pain is necessary prior to treat- ment. ${ }^{24,25}$ Anatomic factors associated with dyspareunia such as scar tissue, pelvic inflammatory disease, vaginal stenosis, or endometriosis often improve with medical or surgical treatment. ${ }^{25}$

Pain of a diffuse, long-term nature is more difficult to treat. ${ }^{24,25}$ In such instances, referral for psychotherapy may prove beneficial. Treatment strategies may include reliance on noncoital sexual expression, counseling focused on less painful coital positions, the use of antidepressants to treat chronic pain syndromes, and anxiety reduction through behavior modification. ${ }^{24,25,28}$

\section{Vaginismus}

Recurrent, involuntary spasm of the outer third of the vagina interfering with intercourse is known as vaginismus. ${ }^{11,25,26}$ In many patients experiencing vaginismus, stresses such as relationship distress or the desire for pregnancy are prominent causative factors..$^{9,11,26}$ Psychological factors typically include strong sexual inhibition, sexual trauma, unexpressed negative feelings toward a sexual partner, or a pain-tension cycle that maintains itself independently of overt psychological factors. ${ }^{9}$

The cornerstone of treatment is centered on the use a series of graduated dilators coupled with relaxation techniques. ${ }^{9}$ Gradual involvement of the partner includes his introduction of the dilators, then fingers, and finally gradual insertion of the penis under the woman's guidance and control. For severely phobic women, additional techniques and systematic desensitization may be necessary. ${ }^{9,24,25,37,38}$

\section{Indications for Referral}

Physicians with appropriate training in sexual medicine should manage the vast majority of women with sexual dysfunction. ${ }^{11,24,37,38}$ However, there are several indications for referrals:

1. Young patients with history of pelvic/perineal trauma;

2. Patients with anorgasmia due to traumatic pudendal neuropathy or hysterectomy;

3. Patients with genital pain due to neuromas, vestibular adenitis myofascial pain syndrome, etc;

4. Patients with aortic aneurysm or bulbosacral disc disease that requires vascular or neurosurgical intervention;

5. Patients with complicated endocrinopathies;

6. Patients with complicated psychiatric or psychosexual disorders (e.g. refractory depression, transsexualism);

7. Patient's or physician's request for specialized evaluation;

8. Forensic reasons (occupational or iatrogenic injuries). 


\section{Specialized Diagnostic Testing}

Neurogenic causes of FSD are currently being investigated. There have been anecdotal reports of the potential lubrication-enhancing effects of phentolamine and sildenafil. ${ }^{54,56}$ Recently, a study published by Kaplan et al., showed that only 6 of the 33 patients treated with sildenafil had a significant therapeutic response ( $>60 \%$ improvement in the index of female sexual function). ${ }^{13}$ This study suggests that sildenafil is safe but has limited efficacy in treating postmenopausal women with self-described sexual dysfunction. Overall sexual function did not improve significantly, although there were changes in vaginal lubrication and clitoral sensitivity. The role of various agents in treating this heretofore under-addressed problem will be an exciting avenue of research in the future.

\section{Treatment of Sexual Dysfunction in Women}

\section{Modifying Reversible Causes}

Health professionals should work with patients to modify reversible causes of FSD such as psychogenic FSD, hormonal imbalances, hyperprolactinemia, specific drugrelated FSD (e.g. selective serotonin reuptake inhibitors SSRIs), vascular or neurologic sexual dysfunction secondary to blunt perineal trauma, and anorgasmia due to pudendal neuropathy. ${ }^{8,11,24,25,37,38}$

\section{Sex steroid hormones}

The role of sex steroid hormones in reproductive function has been extensively investigated and has contributed significantly to the successful clinical management of women with infertility by sex hormones or hormone analogues. ${ }^{52,53}$ However, the role of sex steroid hormones in regulating vaginal arousal has been poorly investigated. At present, there is no rationale for pharmacological management of women with sexual dysfunction by sex hormones or hormone analogues. Sarrel reported that women with plasma estradiol levels less than $50 \mathrm{pg} / \mathrm{mL}$ had significantly more complaints of vaginal dryness, frequency, and intensity of dyspareunia and burning compared to women with estradiol values greater than $50 \mathrm{pg} / \mathrm{mL} .{ }^{57}$ Several investigators have shown that treatment with estradiol increases vaginal blood flow and lubrication, improves epithelial maturation indices, normalizes vaginal $\mathrm{pH}$, and prevents vaginal atrophy. ${ }^{24,38}$ Androgen replacement in women with sexual dysfunction is associated with changes in the external genitalia including increased sensitivity, engorgement, and hypertrophy of the clitoris and vulvar hyperemia. ${ }^{24,45}$ Exogenous administration of androgens has resulted in a significant increase in subjective ratings of sexual arousal in postmenopausal women. Treatment of women with adrenal insufficiency with dehydroepiandrosterone (DHEA) improved overall well-being and sexual function. ${ }^{58,59}$

\section{Hyperprolactinemia}

The treatment of hyperprolactinemia in women with sexual dysfunction consists of 1) cessation of the medication causing hyperprolactinemia (e.g., estrogens, methyldopa), 2) administration of bromocryptine, or 3) the surgical ablation or extirpation of a pituitary prolactin-secreting tumor. ${ }^{11,24,35}$

\section{Iatrogenic/drug-induced}

Psychotropic agents such as SSRIs, neuroleptics, and antipsychotics have been associated with sexual dysfunction in women. ${ }^{41-43}$ In addition, LH-RH agonists and antiandrogens, commonly used in the treatment of endometriosis, infertility, and uterine fibromas are also associated with sexual dysfunction..$^{24,25}$

\section{Psychogenic}

Patients with any kind of destructive behavior, alcoholism, cigarette smoking, or recreational drug use should be counseled on the potential etiologic role of these factors in FSD. ${ }^{9}$

\section{Genital pain}

Genital pain is a highly prevalent (14\%), incapacitating, devastating condition associated with significant personal distress and diminished quality of life. Genital neuromas and vestibular adenitis may be successfully treated by excision of the affected area..$^{24,25}$

\section{FIRST LINE THERAPY}

Oral erectogenic agents (eg sildenafil, apomorphine, oral phentolamine), vacuum erection devices, and psychosexual or couple therapy should be regarded as first-line interventions, on account of ease of administration, reversibility, noninvasive nature, and low cost..

\section{Oral Vasoactive Agents}

Sildenafil, a potent and selective PDE 5 inhibitor that blocks the hydrolysis of cGMP, enhances the accumulation of cGMP and increases the relaxing effects of NO on the clitoris, but it is not currently FDA-approved for use in women. ${ }^{14,22,34,43,44,55,60}$ Sildenafil has been utilized in the treatment of women with sexual arousal disorders with mixed results. ${ }^{43,44,55,60}$ Clinical studies evaluating the efficacy and safety of this drug in women are currently being undertaken. 


\section{Phentolamine}

Phentolamine is a nonselective adrenergic antagonist that decreases adrenergic tone, thus facilitating vasocongestion and delaying detumescence. ${ }^{56}$ A pilot (single dose of oral phentolamine $(40 \mathrm{mg})$ and placebo in a single-blind, dose-escalation) study of 6 postmenopausal women with a lack of lubrication and sexual arousal difficulties reported a mild, positive effect across all measures of arousal, with significant changes in self-reported lubrication and pleasurable sensations in the vagina. ${ }^{56}$ Interestingly, it has been shown that the physiological readings and the subjective reports were significantly different from placebo in the women using estrogen replacement therapy with $40 \mathrm{mg}$ of phentolamine in a vaginal solution. Further studies are needed to assess the potential value of phentolamine and other vasoactive agents in the treatment of FSD.

\section{Vacuum devices}

At the time of writing, this type of therapy is the only FDA-approved treatment for women with sexual dysfunction. ${ }^{24,25,38}$ It is designed to increase blood flow to the clitoris facilitating clitoral engorgement and enhancing peripheral genital sexual arousal. It is generally accepted that clitoral stimulation and engorgement are important aspects of female sexual arousal. It is believed that the difficulty or inability to achieve maximal clitoral tumescence may be related to and associated with other symptoms of female sexual arousal disorder. The postulated increase in blood flow to the clitoris is associated with increased sensation and enhanced sexual arousal including increased vaginal lubrication and labial engorgement.

\section{Sexual Therapy: Individual or Couple}

Sexual therapy addressing relationship distress, sexual performance concerns, and dysfunctional communication patterns is likely to enhance sexual functioning. ${ }^{9,18,24}$ It is recommended that both patient and partner should be involved in the sexual therapy. Sexual therapy is also indicated and beneficial in patients or couples who desire to resume sexual activity after a prolonged period of abstinence. Lastly, sexual therapy is effective in addressing psychological reactions to medical or surgical treatment.

\section{Second and third line therapies}

Unfortunately, there are no second, or third line therapeutic strategies available for the management of women with sexual dysfunction.

\section{CONCLUSION}

In general, the longer-standing the sexual dysfunction, the more difficult it becomes to treat. In addition, the earlier the sexual response cycle is interrupted, the more resilient to treatment it potentially becomes. Therefore, disorders of the desire phase are generally harder to treat than disorders of the arousal phase, which in turn are more difficult to treat than orgasmic dysfunction. Finally, multiple interrelationship sexual dysfunctions such as female anorgasmia coupled with male premature ejaculation, tend to have a synergistic effect and are often more difficult to treat than either alone. As we continue to learn more about the specifics of the sexual response cycle, exciting new treatments will emerge.

It is not the intention of this article to suggest that urologists, geriatrists, or primary care physicians should become the primary caregivers for female sexual health rather than gynecologists. However, it is wise for us to educate ourselves in the identification of female patients with sexual dysfunction. Moreover, as we become more aware of both the basis of diagnosis and of therapy, we can counsel and either effectively treat, or appropriately refer these patients.

\section{RESUMO}

PASQUALOTTO EB e col. Disfunção sexual feminina: o que é importante saber. CLINICS 60(1):51-60, 2005.

A intensa exposição pela mídia do tema disfunção sexual masculina e o número crescente de tratamentos disponíveis para a disfunção erétil têm resultado num número crescente de homens que procuram consulta e tratamento clínico para este problema, antes considerado como "tabu". Uma vez que o problema geralmente surge no contexto do relacionamento, alguns investigadores aludem às taxas crescentes de disfunção sexual nas parceiras destes homens. Além disso, clínicos, ginecologistas, geriatras e urologistas igualmente estão avaliando pacientes do sexo feminino quanto a vários tipos de disfunção. Em alguns grupos de mulheres com condições crônicas subjacentes, também têm sido observado um aumento nas taxas de disfunção sexual concomitante. Médicos que tenham estabelecido uma boa relação médicopaciente estão em posição única para ajudar com este 
problema, que em virtude de sua própria característica de intimidade, geralmente é de difícil abordagem para os pacientes. Desta forma, é de extrema importância que estes profissionais tenham conhecimento e sintam-se à vontade para iniciar a avaliação e possivelmente o tratamento da disfunção sexual feminina.

\section{UNITERMOS: Mulher. Feminina. Sexual. Disfunção.}

\section{REFERENCES}

1. Berard EJ. The sexuality of spinal cord injured women: physiology and pathophysiology. A review. Paraplegia 1989;27:99-112.

2. Lilius HG, Valtonen EJ, Wikstrom J. Sexual problems in patients suffering from multiple sclerosis. J Chronic Dis 1976;29:6437.

3. Schreiner-Engel P, Schiavi R.C, Vietorisz D, Smith H. The differential impact of diabetes type on female sexuality. J Psychosom Res 1987;31:23-33.

4. Kaplan HS, Owett T. The female androgen deficiency syndrome. J Sex Marital Ther 1993;19:3-24.

5. Abdo CH, Oliveira WM, Moreira ED, Fittipaldi JA. Prevalence of sexual dysfunctions and correlated conditions in a sample of Brazilian women - results of the Brazilian study on sexual behavior (BSSB). Int J Impot Res 2004;16:160-6.

6. Schiavi RC, Seagreves RT. The biology of sexual function. Psychiatr Clin North Am. 1995;18:7-23.

7. Goldmeier D, Malik F, Phillips R, Green J. Cost implications of sexual dysfunction: the female picture. Int J Impot Res 2004;16:130-4.

8. Cayan S, Akbay E, Bozlu M, Canpolat B, Acar D, Ulusoy E. The prevalence of female sexual dysfunction and potential risk factors that may impair sexual function in Turkish women. Urol Int 2004;72:52-7.

9. Althof SE, Turner LA, Levine SB, Bodner D, Kursh ED, Resnick MI. Through the eyes of women: the sexual and psychological responses of women to their partner's treatment with selfinjection or external vacuum therapy. J Urol 1992;147:10247.

10. Rosen RC, Taylor JF, Leiblum SR, Bachmann GA. Prevalence of sexual dysfunction in women: results of a survey study of 329 women in an outpatient gynecological clinic. J Sex Marital Ther 1993;19:171-88.

11. Kohn IJ, Kaplan SA. Female sexual dysfunction - What is known and what remains to be determined. Contemporary Urology 1999;11:54-72.

12. Masters WH, Johnson VE. The human female: anatomy of sexual response. Minn Med 1960;43:31-6.

13. Kaplan SA, Reis RB, Kohn IJ, Ikeguchi EF, Laor E, Te AE, et al. Safety and efficiency of sildenafil in postmenopausal women with sexual dysfunction. Urology 1999;53:481-6.

14. Berman JR, Berman LA, Toler SM, Gill J, Haughie S. Sildenafil Study Group. Safety and efficacy of sildenafil citrate for the treatment of female sexual arousal disorder: a double-blind, placebo controlled study. J Urol 2003;170:2333-8.
15. Laumann EO, Paik A, Rosen RC. Sexual dysfunction in the United States: prevalence and predictors. JAMA 1999;281:537-44.

16. Hawton K, Gath D, Day A. Sexual function in a community sample of middle-aged women with partners: effects of age, marital, socioeconomic, psychiatric, gynecological, and menopausal factors. Arch Sex Behav 1994;23:375-95.

17. Spector I, Carey M. Incidence and prevalence of the sexual dysfunctions: a critical review of the empirical literature. Arch Sex Behav 1990;19:389-408.

18. Myers LS, Dixen J, Morissette D, Carmichael M, Davidson JM. Effects of estrogen, androgen, and progestin on sexual psychophysiology and behavior in postmenopausal women. $\mathrm{J}$ Clin Endocrinol Metab 1990;70:1124-31.

19. Nusbaum M, Gamble G, Skinner B, Heiman J. The high prevalence of sexual concerns among women seeking routine gynecological care. J Fam Pract 2000;49:229-32.

20. Berman LA, Berman JR, Werbin T, Chabra S, Goldstein I. The use of the Female Intervention Efficacy Index (FIEI) as an immediate outcome measure of medical intervention to treat female sexual dysfunction. J Sex Marital Ther 2001;27:42733 .

21. Oberg K, Fugl-Meyer AR, Fugl-Meyer KS. On categorization and quantification of women's sexual dysfunctions: an epidemiological approach. Int J Impot Res 2004;16:261-9.

22. Segraves RT. Emerging therapies for female sexual dysfunction. Expert Opin Emerg Drugs 2003;8:515-22.

23. Davis S. Androgen replacement in women: a commentary. J Clin Endocrinol Metab 1999;84:1886-91.

24. Berman JR, Goldstein I. Female Sexual Dysfunction: Urol Clin North Am 2001; 28: 405-416.

25. Berman JR, Berman L, Werbin T, Goldstein I. Female sexual dysfunction: Anatomy, physiology, evaluation and treatment options. Curr Opin Urol 1999;9:563-8.

26. Butcher J. ABC of sexual health: Female sexual problems II: sexual pain and sexual fears. BMJ 1999,318:110-2.

27. Berman JR, Berman LA, Werbin TJ, Flaherty EE, Leahy NM, Goldstein I. Clinical evaluation of female sexual function: effects of age and estrogen status on subjective and physiologic sexual responses. Int J Impot Res 1999; 11: 31-8.

28. Berman JR, Goldstein I. Sildenafil in postmenopausal women with sexual dysfunction. Urology 1999;54:578-9. 
29. Berman JR, Berman LA, Lin H, Marley C, Goldstein I. New Perspectives on anatomy, physiology, evaluation and treatment of female sexual function and dysfunction. A U A Update 2000;34:266-71.

30. Matteo S, Rissman EF. Increased sexual activity during the midcycle portion of the human menstrual cycle. Horm Behav 1984;18:249-55.

31. Davis SR, McCloud P, Strauss BJ, Burger H. Testosterone enhances estradiol's effects on postmenopausal bone density and sexuality. Maturitas 1995;21:227-36

32. Sherwin BB, Gelfand MM, Brender W. Androgen enhances sexual motivation in females: a prospective, crossover study of sex steroid administration in the surgical menopause. Psychosom Med 1985;47:339-51.

33. Sherwin BB, Gelfand MM. The role of androgen in the maintenance of sexual functioning in oophorectomized women. Psychosom Med 1987;49:397-409.

34. DasGupta R, Wiseman OJ, Kanabar G, Fowler CJ, Mikol DD. Efficacy of sildenafil in the treatment of female sexual dysfunction due to multiple sclerosis. J Urol 2004;171:118993.

35. Weizman R, Weizman A, Levi J, Gura V, Zevin D, Maoz B, et al. Sexual dysfunction associated with hyperprolactinemia in males and females undergoing hemodialysis. Psychosom Med $1983 ; 45: 259-69$.

36. Sipski ML, Alexander CJ, Rosen RC. Orgasm in women with spinal cord injuries: a laboratory-based assessment. Arch Phys Med Rehabil 1995;76:1097-102.

37. Laumann E, Paik A, Rosen R. Sexual dysfunction in the United States: prevalence and predictors. JAMA 1999;281:537-44.

38. Berman JR, Berman L, Goldstein I. Female sexual dysfunction: incidence, pathophysiology, evaluation, and treatment options. Urology 1999;54:385-91.

39. Jensen PT, Groenvold M, Klee MC, Thranov I, Petersen MA, Machin D. Early-stage cervical carcinoma, radical hysterectomy, and sexual function A longitudinal study. Cancer 2004;100:97-106.

40. Nusbaum M, Gamble G, Skinner B, Heiman J. The high prevalence of sexual concerns among women seeking routine gynecological care. J Fam Pract 2000;49:229-32.

41. Meston CM, Gorzalka BB. Psychoactive drugs and human sexual behavior: the role of serotonergic activity. J Psychoactive drugs $1992 ; 24: 1-40$

42. Hirschfeld RM. Long-term side effects of SSRIs: sexual dysfunction and weight gain. J Clin Psychiatry 2003;64:20-4.

43. Shen WW, Urosevich Z, Clayton DO. Sildenafil in the treatment of female sexual dysfunction induced by selective serotonin reuptake inhibitors. J Reprod Med 1999;44:535-42.

44. Nurnberg HG, Duttagupta S. Economic analysis of sildenafil citrate (Viagra) add-on to treat erectile dysfunction associated with selective serotonin reuptake inhibitor use. Am J Ther 2004;11:912 .
45. Hodgins MB, Spike RC, Mackie RM, MacLean AB. An immunohistochemical study of androgen, oestrogen and progesterone receptors in the vulva and vagina. Br J Obstet Gynaecol 1998;105:216-22.

46. Goldstein I, Berman J. Vasculogenic female sexual dysfunction. Int J Impot Res 1998;10:84-90.

47. Park K, Goldstein I, Andry C, Siroky MB, Krane RJ, Azadzoi KM Vasculogenic female sexual dysfunction: the hemodynamic basis for vaginal engorgement insufficiency and clitoral erectile insufficiency. Int J Impot Res 1997,9:27-37.

48. Tarcan T, Park K, Goldstein I, Maio G, Fassina A, Krane RJ, et al. Histomorphometric analysis of age-related structural changes in human clitoral cavernosal tissue. J Urol 1999;161:940-4.

49. Shifren JL, Braunstein GD, Simon JA, Casson PR, Buster JE, Redmond GP, et al. Transdermal testosterone treatment in women with impaired sexual function after oophorectomy. N Engl J Med 2000;343:682-8

50. Levin RJ. The female orgasm-a current appraisal. J Psychosom Res 1981; 25:119-33

51. Kaplan HS. Hypoactive sexual desire. J Sex Marital Ther 1977;3:39

52. Adashi EY. The climacteric ovary as a functional gonadotropindriven androgen- producing gland Fertil Steril 1994;62:20-7.

53. Rako S. Testosterone supplemental therapy after hysterectomy with or without concomitant oophorectomy: estrogen alone is not enough. J Womens Health Gend Based Med 2000;9:91723.

54. Min K, Kim NN, McAuley I, Stankowicz M, Goldstein I, Traish $\mathrm{AM}$, et al. Sildenafil augments pelvic nerve-mediated female genital sexual arousal in the anesthetized rabbit. Int J Impot Res 2000;12:S32-9.

55. Park K, Moreland RB, Goldstein I, Atala A, Traish A. Characterization of phosphodiesterase activity in human clitoral corpus cavernosum smooth muscle cells in culture. Biochem Biophys Res Commun 1998;249:612-7.

56. Rosen RC, Phillips NA, Gendrano NC $3^{\text {rd }}$, Ferguson DM. Oral phentolamine and female sexual arousal disorder: A pilot study. J Sex Marital Therapy 1999;25:137-44.

57. Sarrel PM. Androgen deficiency: menopause and estrogen-related factors. Fertil Steril 2002;77:S63-7.

58. Baulieu EE, Thomas G, Legrain S, Lahlou N, Roger M, Debuire B, et al. Dehydroepiandrosterone (DHEA), DHEA sulfate, and aging: contribution of the DHE Age Study to a sociobiomedical issue. Proc Natl Acad Sci U S A 2000;97:4279-84.

59. Arlt W, Callies F, van Vlijmen JC, Koehler I, Reincke M, Bidlingmaier $\mathrm{M}$, et al. Dehydroepiandrosterone replacement in women with adrenal insufficiency. N Engl J Med 1999; 341:1013-20.

60. Berman JR, Berman LA, Lin H, Flaherty E, Lahey N, Goldstein I et al. Effect of sildenafil on subjective and physiologic parameters of the female sexual response in women with sexual arousal disorder. J Sex Marital Ther 2001;27:411-20. 